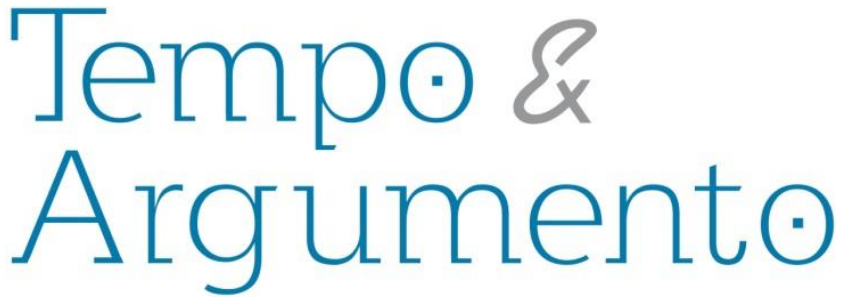

\title{
Um olhar sobre a dimensão cultural dos protestos e os dilemas
} da mobilização

\section{Resenha da obra:}

JASPER, James M. Protesto: uma introdução aos movimentos sociais. Tradução: Carlos Alberto Medeiros. $1^{\text {a }}$ ed. Rio de Janeiro: Zahar, 2016.

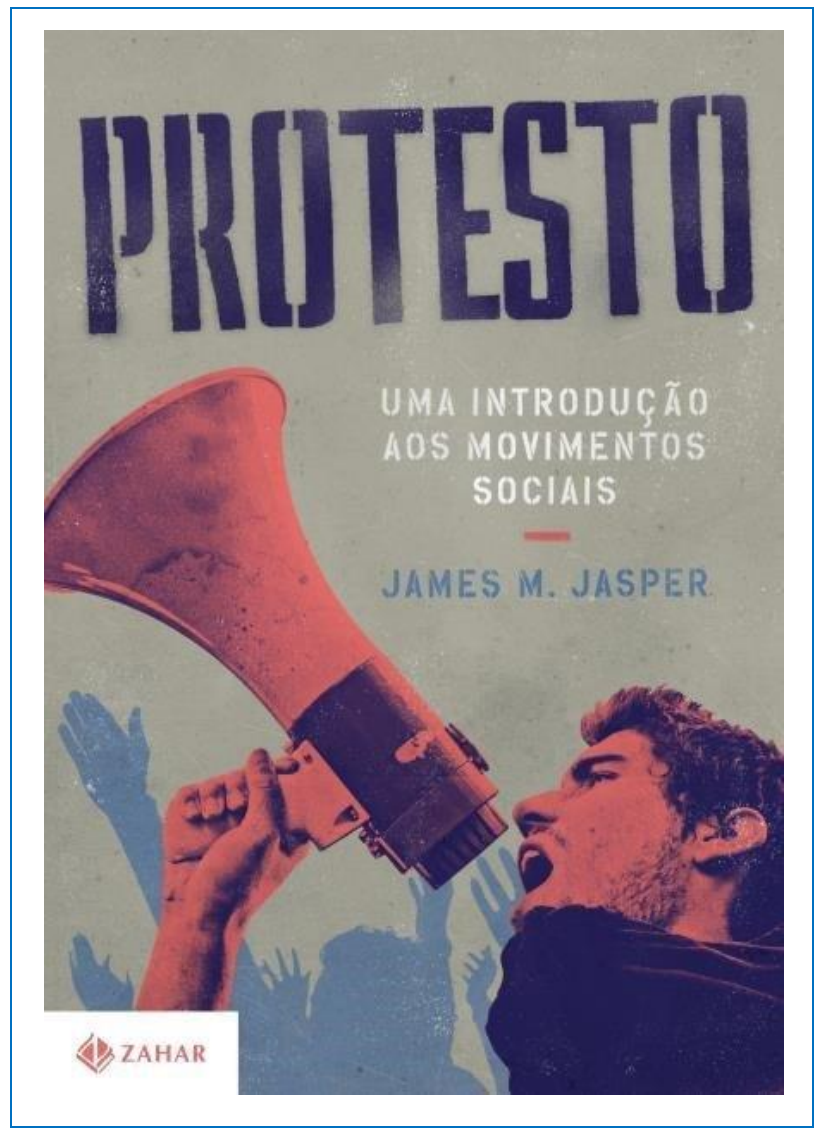

\section{Autor da resenha}

\section{Arnaldo José Zangelmi}

Doutor em Ciências Sociais, Desenvolvimento, Agricultura e Sociedade pela Universidade Federal Rural do Rio de Janeiro. Professor na Universidade Federal de Ouro Preto (UFOP).

Mariana - MG - Brasil arnaldozan@yahoo.com.br

\section{Para citar esta resenha:}

JASPER, James M. Protesto: uma introdução aos movimentos sociais. Tradução: Carlos Alberto Medeiros. $1^{\text {a }}$ ed. Rio de Janeiro: Zahar, 2016. Resenha de: ZANGELMI, Arnaldo José. Um olhar sobre a dimensão cultural dos protestos e os dilemas da mobilização. Revista Tempo e Argumento, Florianópolis, v. 10, n. 25, p. 502 - 508. jul/set. 2018. 
Publicada originalmente pela editora Polity em 2014, com o título Protest: a cultural Introduction to social movements, a obra aqui apresentada foi disponibilizada em português pela Zahar no ano de 2016, em edição que conta com prefácio e posfácio dedicados especialmente ao contexto brasileiro. James Macdonald Jasper, professor da City University of New York, busca compreender as dinâmicas de mobilização em diversos contextos, dando especial atenção à dimensão cultural dos protestos. Apesar do reconhecimento sobre a relevância das forças estruturais, a atenção do autor está direcionada principalmente para as significações, emoções, valores morais e estratégias de ação dos atores em interação nas diversas arenas.

O livro é formado por oito capítulos, cada um baseado na articulação entre as mobilizações de um determinado movimento e um dos aspectos centrais nas dinâmicas dos movimentos em geral. Ao longo da obra, o autor também relaciona reflexões sobre os movimentos mais recentes e processos históricos mais antigos, como o caso de John Wilkes, ator que desencadeou uma série de movimentos na Inglaterra do século XVIII.

O primeiro capítulo é voltado principalmente para as definições e abordagens sobre os movimentos sociais. Jasper traça um breve panorama das principais perspectivas, delimitando entre as teorias psicológicas (ressentimento, multidões, escolha racional etc.), estruturalistas (oportunidades políticas, mobilização de recursos etc.) e históricas (Marx, Touraine, Tilly etc.). O autor busca, então, demonstrar como essas várias tendências, quando isoladas, se mostraram incapazes de compreender a realidade social, problema que tem levado algumas delas a incorporar a dimensão cultural em suas análises. Um exemplo é o sociólogo estadunidense Charles Tilly, que incorporou a persuasão como elemento relevante em seus últimos trabalhos. Jasper embasa parte significativa de suas reflexões nas concepções conceituais e históricas de Tilly, especialmente sobre as mudanças nos repertórios de ação dos movimentos nos séculos XVIII e XIX, em países como França e Grã-Bretanha.

O segundo capítulo trata da construção e projeção de significados, utilizando o movimento feminista como principal referencial empírico. Jasper salienta como a feminilidade é uma construção cultural, não um imperativo biológico, sendo assim foco das mobilizações de diversos movimentos ao longo da história. O movimento feminista, 
por diversos meios físicos e figurativos, buscou transformar as significações vigentes, influenciar a sociedade e conquistar novos direitos.

No terceiro capítulo, o autor trata das infraestruturas (comunicações, transporte, redes sociais, organizações, profissionais etc.) nas quais os atores se mobilizam, espaços que influenciam no processo de criação e transmissão de significados culturais pelos movimentos. Tratando especialmente das mobilizações da direita cristã nos Estados Unidos, Jasper deixa entrever que sua perspectiva tem um forte caráter relacional, na medida em que argumenta que o surgimento e desenvolvimento dos movimentos se dão nas interações com outros atores em diversas arenas. Assim, o autor demonstra como as ações de religiosos conservadores tiveram como principais contrapontos o feminismo e o movimento LGBTQ, se constituindo, em grande medida, pelo contraste em seus enfrentamentos.

As análises de Jasper também têm um enfoque processual, pois abordam as continuidades e transformações nas formas de enfrentamento, demonstrando como antigos movimentos deram base para novas mobilizações. Nesse sentido, o autor explica como os conservadores da direita cristã tiveram influência do anticomunismo dos anos de 1950, assim como os movimentos de homossexuais se valeram das linguagens de direitos praticadas pelos movimentos de afro-americanos, mulheres, indígenas etc. da década de 1960.

A partir dessas análises, o autor critica o uso de diferentes teorias para explicar movimentos de esquerda e direita, uma das tendências entre os estudiosos dos movimentos sociais. Assim, Jasper enfatiza a necessidade de superarmos os relatos que apontam motivações psicológicas e patológicas para os movimentos de direita, sendo mais proveitoso buscar compreender as formas como esses atores significam suas ações.

A dinâmica de recrutamento de novos membros nos movimentos é discutida no quarto capítulo, que analisa o movimento LGBTQ. O autor destaca o relevante papel dos contatos pessoais, em redes formais e informais, como incentivos para o ingresso e permanência nas mobilizações. Assim, as relações de confiança pré-existentes, orientações afetivas e intuições morais são elementos fundamentais para a adesão aos movimentos. 
O desenvolvimento das mobilizações dos homossexuais nos EUA é um bom exemplo também para o que o autor denomina como "dilema da desobediência ou cordialidade", no qual os atores se deparam com escolhas entre táticas aceitas, que geram simpatia de outros atores, ou ações temidas que podem alcançar maior orgulho pelo grupo e recuo dos adversários, porém com maior risco de repulsa e repressão. Quando surgiu a epidemia de AIDS no início dos anos de 1980, assim como sua conotação depreciativa pela direita cristã, a ascendente mobilização das comunidades gays se direcionou para cuidados com os moribundos e a busca por aparência de normalidade e amorosidade. No entanto, os crescentes avanços conservadores sobre as políticas públicas, ocasionaram duras formas de discriminação, causaram um "choque moral” e um crescente sentimento de indignação entre os gays a partir da segunda metade da década de 1980, atraindo milhares de militantes, muitos deles jovens.

O “choque moral” é uma reação emocional que gera sentido de urgência, ameaça, indignação e medo. Desencadeado por eventos dramáticos que quebram a rotina, ele abala o senso de realidade e normalidade, sendo forte motivador para a ação. Assim, houve uma guinada no sentido da desobediência, inconformidade, enfrentamento no movimento LGBTQ, que canalizou a culpa e a vergonha para o Estado, sistematicamente homofóbico, assim como para outras instituições conservadoras da sociedade.

A questão da manutenção dos membros em um movimento é discutida no quinto capítulo, que destaca as diversas satisfações e incentivos promovidos nos movimentos, como a identificação com o grupo, o sentimento de estar fazendo história, o senso de pertencimento etc. Jasper buscou demonstrar como as mobilizações dos dalits, na busca por direitos contra o hinduísmo bramânico dominante, caminharam no sentido da transformação da vergonha em orgulho para o grupo.

O sexto capítulo é voltado para a análise dos processos decisórios nos movimentos, tendo como base o movimento por justiça global. Mobilizando-se principalmente através de fóruns, entre os quais o Fórum Social Mundial tem maior expressão, esses atores têm formulado fortes críticas às políticas neoliberais de diversos países. Jasper analisa diversos mecanismos de tomada de decisão, como a formação de consensos, disputas pelo voto etc. O autor salienta as tensões entre as discussões horizontais, que demandam mais tempo, e as necessidades de tomada de decisão mais 
rápida e incisiva. Jasper demonstra como as rotinas organizacionais, ao cristalizarem certos procedimentos, diminuem a necessidade de muitas discussões, porém com prejuízo da criatividade e flexibilidade no processo decisório. O autor destaca também que as discordâncias entre facções, a respeito dos objetivos, estratégias etc., podem caminhar para a conciliação ou cismas nos grupos. Assim, mostra como as alianças são dinâmicas, influenciadas por uma multiplicidade de fatores, gerando grande incerteza nessas interações.

O sétimo capítulo trata da revolução egípcia, principalmente quanto às interações dos diversos grupos, entre os anos de 2011 e 2013. Jasper discute como outros atores se envolvem nas mobilizações, em complexas teias de alianças e disputas nas várias arenas. Assim, busca demonstrar como exército, governo norte-americano, grupos religiosos, partidos políticos etc. interagiram nesse processo, influenciando seus rumos. Dessa forma, o autor argumenta que os diversos grupos, cada qual com métodos e objetivos próprios, se envolvem numa mistura de cálculo e emoção, coerção e persuasão. A eficácia dos movimentos, em grande medida, depende de sua capacidade de envolver outros atores numa mesma causa.

No oitavo capítulo, Jasper discute as vitórias, derrotas e demais impactos dos movimentos sociais no mundo contemporâneo, tendo como referencial empírico central o movimento pelos direitos dos animais, principalmente na Grã-Bretanha e nos EUA. Esse movimento obteve várias conquistas, como leis que reduziram consideravelmente o sofrimento dos animas, mas enfrenta fortes obstáculos relacionados a hábitos arraigados, mercado, pesquisas científicas etc. Jasper argumenta que, além das conquistas concretas, vale atentar para os impactos nas visões de mundo, nas sensibilidades morais e interpretações históricas das sociedades. Os movimentos sociais transformam as maneiras de sentir e pensar, conduzindo, mesmo indiretamente, para novas práticas. Os integrantes dos movimentos sociais mudam também a si mesmos, desenvolvendo pensamento crítico, confiança e hábitos que os acompanham em suas trajetórias. Antigos movimentos inspiram os novos e também abrem espaços ao transformarem as regras das diversas arenas, potencializando as lutas futuras.

Jasper procura tecer algumas considerações sobre os movimentos no Brasil, principalmente no prefácio e posfácio à edição brasileira. O autor reflete sobre os 
protestos desencadeados a partir de 2013, enfatizando como as mobilizações contra o aumento das passagens, com proeminência do movimento Passe Livre, envolveram outros atores e catalisaram demandas mais amplas. Numa guinada para novos rumos, destoantes dos originais, esse processo culminou com a contundente queda presidencial, algo ainda efervescente em nossa sociedade. Retrocedendo um pouco mais em nossa história recente, Jasper também discute a importância do choque moral causado pelos massacres de Corumbiara e Eldorado dos Carajás que, ao gerarem indignação, impulsionaram o governo FHC no sentido das reivindicações do MST no final da década de 1990. Por fim, enfatiza como a tática das ocupações ajudou a inspirar outros movimentos pelo mundo, como se pode ver em vários movimentos da atualidade.

Apesar de parte significativa dos problemas tratados por Jasper nesse livro já terem sido discutidos por outros estudos ${ }^{1}$, sua abordagem traz contribuições relevantes, na medida em que enfatiza as dimensões mais subjetivas dos movimentos, como a produção de significados, estratégias, sentimentos, efeitos morais etc. Essa ênfase é concretizada principalmente na sua exposição de certas questões como "dilemas" delimitação original que direciona a atenção para a perspectiva dos atores em suas interações concretas e suas escolhas diante dos universos de possibilidades que vislumbram.

O livro apresenta tanto uma visão introdutória e abrangente quanto profundidade analítica sobre os movimentos sociais, o que o torna interessante para os estudos de iniciantes e especialistas no tema, assim como para que militantes possam revisitar e reinventar suas práticas. Também se trata de uma obra profundamente atual, dado o crescente impacto dos protestos na dinâmica política recente. Entender os movimentos sociais e os protestos é, cada vez mais, algo imprescindível e estimulante para aqueles que se dispõem a conhecer e buscar transformar o mundo de hoje.

\footnotetext{
1 É sugestiva a aproximação entre o que Jasper denomina como "dilema de Jano" e a "lógica dual" retratada por Cohen \& Arato (2000), assim como os dilemas da "mídia" e "da cordialidade e desobediência" encontram em Champagne (1996) questões comuns. Algumas discussões sobre as dinâmicas das organizações de movimentos sociais (Cefai, 2009. Neveu, 2005) também abordam problemas similares ao "dilema da organização" de Jasper que, no entanto, coloca essas questões noutras perspectivas.

${ }^{2}$ Os principais dilemas analisados são: dilema de Jano, dilema das mãos sujas, dilema da caracterização dos personagens, dilema da inovação, dilema da mídia, dilema da organização, dilema da expansão, dilema da desobediência e cordialidade, dilema da identidade, dilema dos irmãos de sangue, dilema dos aliados poderosos, dilema da segregação do público e dilema da articulação.
} 
